\title{
Luminescence Properties of Impurity-Doped Zinc Oxide Phosphor for Novel Neutron Detection
}

\author{
Hidehito Nanto, ${ }^{*}$ Mizuha Sato, Yuka Miyamoto, ${ }^{1}$ Kazuki Hirasawa, \\ Yoshinori Takei, Takayuki Yanagida, ${ }^{2}$ Tatsuya Nakamura, ${ }^{3}$ and Masaki Katagiri ${ }^{4}$ \\ Advanced Materials Science R\&D Center, Kanazawa Institute of Technology, \\ 3-1 Yatsukaho, Hakusan, Ishikawa 924-0838, Japan \\ 'Oarai Research Center, Chiyoda Techno Co. Ltd., 3681 Narita-Cho, Oarai-machi, Ibaraki 311-1313, Japan \\ ${ }^{2}$ Nara Institute of Science and Technology, 8916-5 Takayama, Ikoma, Nara 630-0192, Japan \\ ${ }^{3}$ Japan Atomic Energy Agency, 765-1 Tokaimura, Nakagun, Ibaraki 319-1195, Japan \\ ${ }^{4}$ Ibaraki University, 2 Bunkyou, Mito, Ibaraki 310-0056, Japan
}

(Received December 28, 2015; accepted May 6, 2016)

Keywords: zinc oxide, exciton emission, neutron, scintillator, ionizing radiation

A neutron detection sheet composed of Ag-doped zinc sulfide $(\mathrm{ZnS})$ as a scintillator and ${ }^{6} \mathrm{LiF}$ as a neutron converter has been conventionally used for neutron detection, and as an imaging detector using the photon counting method, because of its high luminescence rate for neutrons. However, the weak point in a Ag-doped $\mathrm{ZnS}$ scintillator is the slow component of its lifetime. Thus, we began to investigate other II-VI compound phosphors without the slow component of its lifetime for neutron detectors using the photon counting method. In this study, $\mathrm{Cu}-$, In-, Al-, and Gaimpurity-doped $\mathrm{ZnO}$ phosphors without the slow component of lifetime for neutron detectors at a high counting rate have been fabricated using a spark plasma sintering method. It was found that Ga-doped $\mathrm{ZnO}$ exhibited the highest intensity of luminescence at a wavelength of $383 \mathrm{~nm}$. The intensity of the $383 \mathrm{~nm}$ luminescence due to exciton emission with a lifetime of about 4 ns was comparable to that of the $\mathrm{Ag}$-doped $\mathrm{ZnS}$ phosphor with a lifetime of about $220 \mathrm{~ns}$, indicating that the Ga-doped $\mathrm{ZnO}$ phosphor could be used as a promising phosphor material for a neutron image sensor. It was also found that the luminescence intensity of the Ga-doped $\mathrm{ZnO}$ phosphor samples did not decrease when $\mathrm{B}_{2} \mathrm{O}_{3}$ was added as a neutron-alpha (n, alpha) converter. It was confirmed that a Ga-doped $\mathrm{ZnO}$ scintillator with $\mathrm{B}_{2} \mathrm{O}_{3}$ converter responds to the neutron beam emitted by the Japan Research Reactor-3 (JRR-3).

\section{Introduction}

Recently, the next-generation pulsed neutron source using a high-intensity proton accelerator has been constructed in Japan Proton Accelerator Research Complex (J-PARC) project. It is expected that the pulsed neutron source can emit powerful neutrons which are incident to detectors within short time. ${ }^{(1)}$ At the experimental sites, a novel neutron detector that can detect neutrons one by one is necessary. Currently, a neutron imaging detector using Ag-doped zinc sulfide ( $\mathrm{ZnS}$ ) phosphors covered with neutron-alpha converters is used as a neutron scintillator, because the luminescence from the Ag-doped $\mathrm{ZnS}$ phosphor for alpha rays is higher than that of other phosphors, and its

*Corresponding author: e-mail: hnanto@neptune.kanazawa-it.ac.jp 
lifetime is about $200 \mathrm{~ns}$, which is relatively short. The weak point of the Ag-doped $\mathrm{ZnS}$ phosphor is the slow component of its luminescence lifetime, which is about $0.1 \mathrm{~ms}^{(1)}$ For this reason, the maximum counting rate is about $100 \mathrm{kcps}$ in neutron detectors using a ${ }^{6} \mathrm{LiF} / \mathrm{Ag}$-doped $\mathrm{ZnS}$ sheet. It is difficult to use the Ag-doped $\mathrm{ZnS}$ phosphor for the detection of a high-intensity neutron beam from a highly intense proton accelerator owing to the pile-up phenomenon, as shown in Fig. 1. We began to investigate other II-VI compound semiconductors without a slow component of lifetime; consequently, we have become interested in zinc oxide $(\mathrm{ZnO})$ with an exciton luminescence with a very short lifetime.

Since $\mathrm{ZnO}$ is a direct-band-gap II-VI compound semiconductor with a $3.37(\mathrm{eV})$ band gap energy that is stable over a wide range of temperatures and is mechanically robust, some compounds based on $\mathrm{ZnO}$ have been considered as promising materials for fast scintillators, ${ }^{(2-6)}$ ultraviolet (UV) emitters, ${ }^{(7,8)}$ transparent conducting oxides, ${ }^{(9,10)}$ and gas sensors. ${ }^{(11-13)}$ Recently, an efficient ultrafast scintillation in the UV wavelength region has been observed in Ga- and In-doped $\mathrm{ZnO}$ phosphors, because room-temperature exciton emission with ultrafast (about $4 \mathrm{~ns}$ ) is observed in $\mathrm{ZnO}$ phosphors with large exciton bonding energies. ${ }^{(14,15)}$ In this paper, we report the optical and structural properties of a $\mathrm{ZnO}$ phosphor prepared using the spark plasma sintering (SPS) method. This phosphor could be useful as neutron detectors for high-power neutron beams.

\section{Experimental Procedure}

Each powder mixture (purity of 99.99\%) of $\mathrm{ZnO}$ containing copper oxide $(\mathrm{CuO})$, aluminum oxide $\left(\mathrm{Al}_{2} \mathrm{O}_{3}\right)$, indium oxide $\left(\mathrm{In}_{2} \mathrm{O}_{3}\right)$, and gallium oxide $\left(\mathrm{Ga}_{2} \mathrm{O}_{3}\right)$ was sintered using a conventional SPS system (SPS Syntax Inc). The $\mathrm{B}_{2} \mathrm{O}_{3}$ and $\mathrm{H}_{3}{ }^{10} \mathrm{BO}_{3}$ powders as neutron converter materials were supplied by the Japan Atomic Energy Association.

Powdered mixtures of $\mathrm{ZnO}$, supplied by Hakusui Chemicals Co., Ltd, Furuuchi Chemicals Co., Ltd., and Kojundo Chemicals Co., Ltd., were sintered at $750{ }^{\circ} \mathrm{C}$ for 30 min using the SPS apparatus in vacuum at a pressure of 7-10 Pa. Pulsed currents of about $300 \mathrm{~A}$ were applied to the $\mathrm{ZnO}$ mixture without applying compressed pressure. In order to anneal the $\mathrm{ZnO}$ powder in vacuum, the sintering of the $\mathrm{ZnO}$ powder using the SPS apparatus was carried out in vacuum without pressure

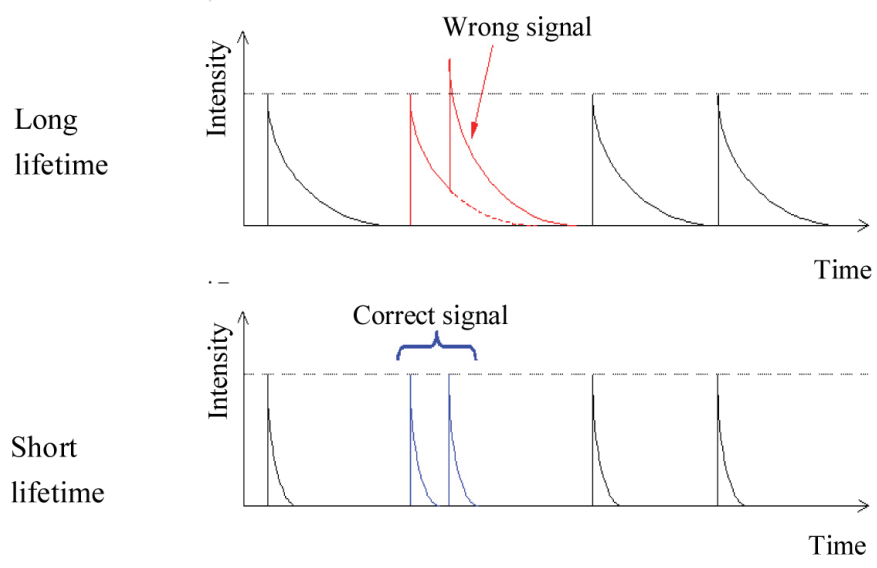

Fig. 1. (Color online) Schematic diagram of the pile-up phenomenon. 
by external mechanical force. Details of the preparation of sintered $\mathrm{ZnO}$ phosphors have been reported in previous papers. ${ }^{(16-18)}$

As for the crystallinity measurement of the $\mathrm{ZnO}$ phosphors, their crystallographic structure was evaluated using an X-ray diffraction (XRD) apparatus (Rigaku Electric Co. Ltd., Model: RINT2000, Cu target, $40 \mathrm{kV} / 30 \mathrm{~mA}$ ). Photoluminescence (PL) spectra caused by excitation with UV light $(330 \mathrm{~nm})$ were observed using a Hitachi F-3010 spectrofluorometer at room temperature. The radioluminescence was observed by excitation with alpha rays from a ${ }^{241} \mathrm{Am}$ source. The PL and radioluminescence spectra were corrected for the diffraction efficiency of the grating and the optical response of the photomultiplier.

\section{Results and Discussion}

\subsection{PL characteristics of undoped $\mathrm{ZnO}$ and impurity-doped $\mathrm{ZnO}$ phosphor}

In order to optimize the phosphor materials composition, the luminescence properties of $\mathrm{ZnO}$ phosphors was evaluated using the PL spectra by excitation with $330 \mathrm{~nm}(3.76 \mathrm{eV})$ light, because of ease of measurement. It is possible to perform band-to-band excitation using $360 \mathrm{~nm}$ light as an excitation source for luminescence measurement, because the energy $(3.76 \mathrm{eV})$ of such excitation light is larger than the band gap energy of $\mathrm{ZnO}$ (about $3.37 \mathrm{eV}$ ).

The PL spectra of undoped $\mathrm{ZnO}$ phosphors from three different suppliers are shown in Fig. 2. It can be seen that the PL spectrum consists of two emission bands: a broad visible emission band (at about $450 \mathrm{~nm}$ ) and a very sharp UV emission band (at about $380 \mathrm{~nm}$ ). It can also be seen that the luminescence intensity and spectral shape are strongly dependent on the $\mathrm{ZnO}$ powder supplier. The differences in the spectral shape may be understood from the crystal size and type of impurity in the phosphor; they are different from sample to sample, because previous reports ${ }^{(18,19)}$ suggest that the visible and UV emission bands are ascribed to native-defect-associated emission and exciton-type emission, respectively.

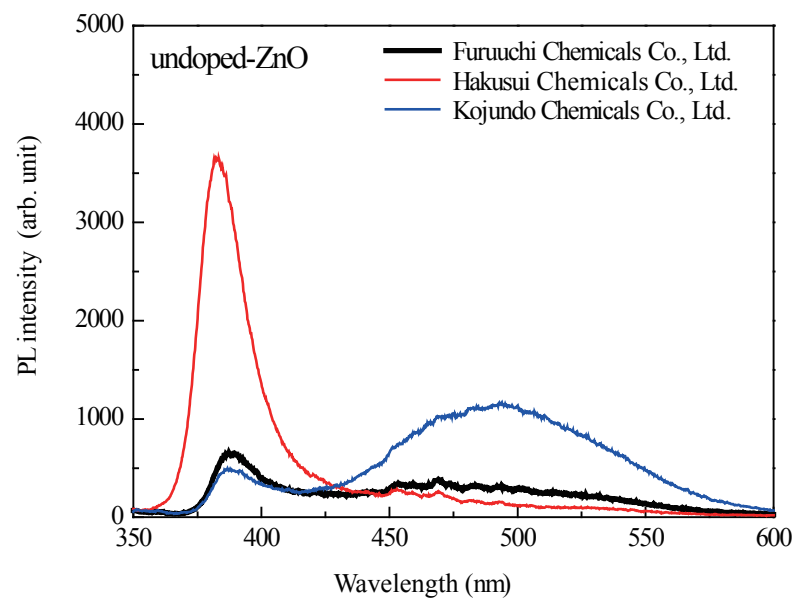

Fig. 2. (Color online) Typical PL spectra of undoped $\mathrm{ZnO}$ phosphors prepared by the SPS method using the 4N ZnO powders supplied by Hakusui Chemicals Co., Ltd., Furuuchi Chemicals Co., Ltd., and Kojundo Chemicals Co., Ltd. 
Typical PL spectra of undoped $\mathrm{ZnO}$ phosphors that were uncrushed but then crushed in the crucible before heat treatment are shown in Fig. 3. The spectra indicate that the ratio of the visible emission band to the UV emission band depends on how crushed the $\mathrm{ZnO}$ powder is. The difference in the ratio between the visible and UV bands is ascribed to the difference in the homogeneity of crystal size, because the crystallinity and homogeneity of crushed $\mathrm{ZnO}$ powder are better than those of uncrushed $\mathrm{ZnO}$ powder.

The lifetimes of the visible and UV emission bands were about 240 and 4 ns, respectively, as reported previously. ${ }^{(20)}$ The lifetime (about $4 \mathrm{~ns}$ ) of the UV emission band is fairly shorter than that (about $220 \mathrm{~ns}$ ) of the main emission band in a commercially available Ag-doped $\mathrm{ZnS}$ scintillator. ${ }^{(18)}$

To fabricate a $\mathrm{ZnO}$ scintillator emitting only UV light, $\mathrm{ZnO}$ (purity: $4 \mathrm{~N}$ ) phosphors doped with impurities such as $\mathrm{CuO}, \mathrm{Al}_{2} \mathrm{O}_{3}, \mathrm{In}_{2} \mathrm{O}_{3}$, and $\mathrm{Ga}_{2} \mathrm{O}_{3}$ were prepared using the SPS method. Two types of $\mathrm{ZnO}$ powder, which were supplied by Furuuchi Chemicals Co., Ltd. and Hakusui Chemicals Co., Ltd., were used as the mother phosphor materials. The powder mixture of $\mathrm{ZnO}$ doped with $\mathrm{CuO}$, $\mathrm{Al}_{2} \mathrm{O}_{3}, \mathrm{In}_{2} \mathrm{O}_{3}$, or $\mathrm{Ga}_{2} \mathrm{O}_{3}$ powder was crushed for 40 min before heat treatment.

Figure 4 shows typical PL spectra of the $\mathrm{Cu}$-doped $\mathrm{ZnO}$ phosphor (Furuuchi Chemicals Co., Ltd.) compared with those of an undoped $\mathrm{ZnO}$ phosphor. The concentration of $\mathrm{CuO}$ dopant was changed from 0.01 to $0.1 \mathrm{~mol} \%$. It can be seen that $\mathrm{Cu}$ doping was not effective in reducing the intensity of the visible emission band in the PL spectrum, although it is expected that substitutional $\mathrm{Cu}$ atoms will act as acceptors in the $\mathrm{ZnO}$ phosphor.

Figure 5 shows typical PL spectra of an Al-doped $\mathrm{ZnO}$ phosphor in which the $\mathrm{Al}_{2} \mathrm{O}_{3}$ concentration was changed from 0.03 to $0.15 \mathrm{~mol} \%$. In this case, the $\mathrm{ZnO}$ powder from Furuuchi Chemicals Co., Ltd. was used as the mother phosphor material. It can be seen that doping was not effective in reducing the intensity of the visible emission band.

It was found that In and Ga doping among group III elements such as Al, In, and $\mathrm{Ga}$ as donors in $\mathrm{ZnO}$ is effective in reducing the intensity of the visible emission band and increasing the intensity of the UV emission band. It was confirmed that the intensity of the UV emission band in a Ga-

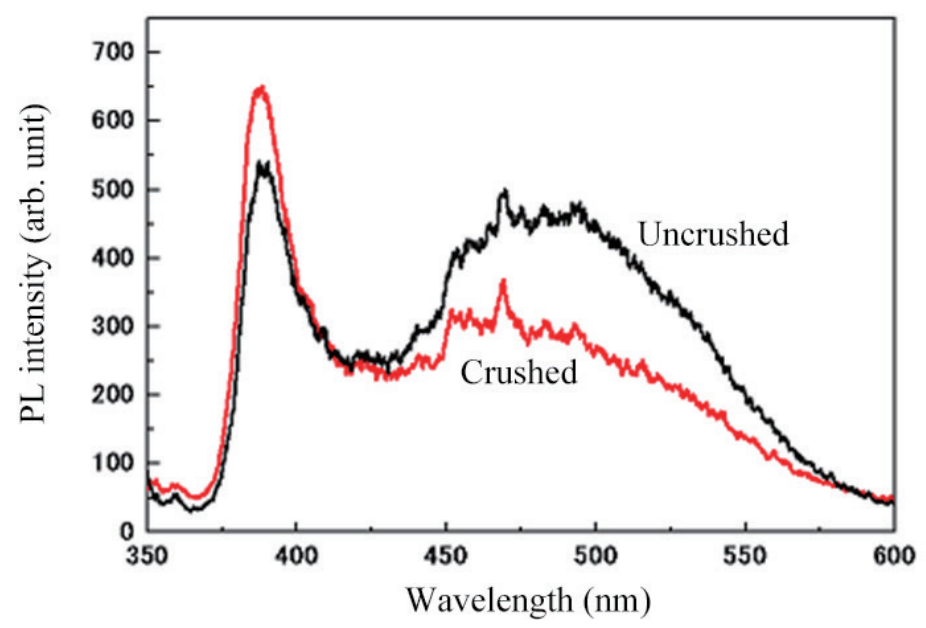

Fig. 3. (Color online) Typical PL spectra of an undoped $\mathrm{ZnO}$ phosphor. One portion of the $\mathrm{ZnO}$ phosphor powder supplied by Furuuchi Chemicals Co., Ltd., was crushed for $40 \mathrm{~min}$, and another was placed uncrushed in a crucible before heat treatment. 


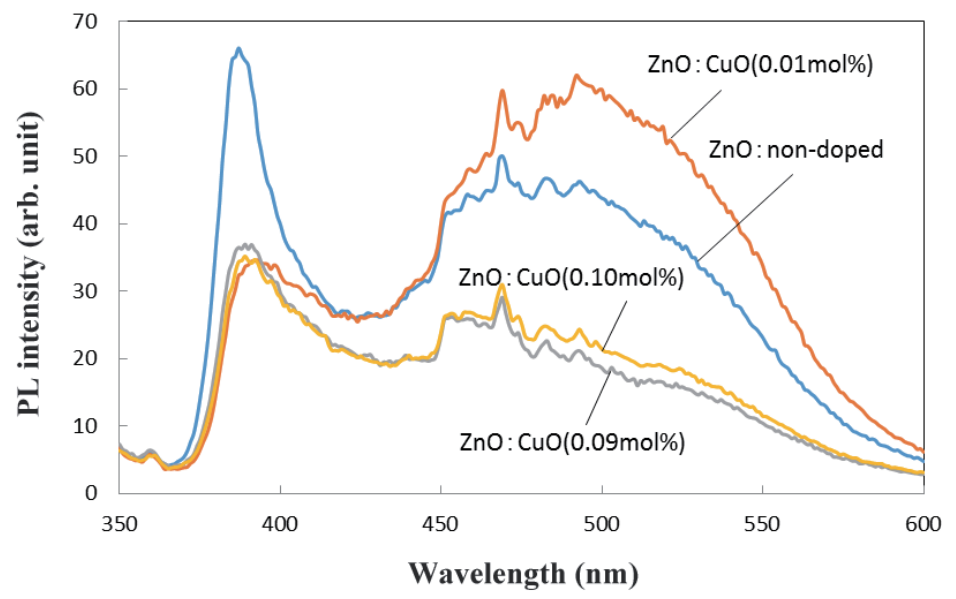

Fig. 4. (Color online) Typical PL spectra of $\mathrm{Cu}$-doped $\mathrm{ZnO}$ phosphors compared with those of undoped $\mathrm{ZnO}$ phosphor (Furuuchi Chemicals Co., Ltd.).

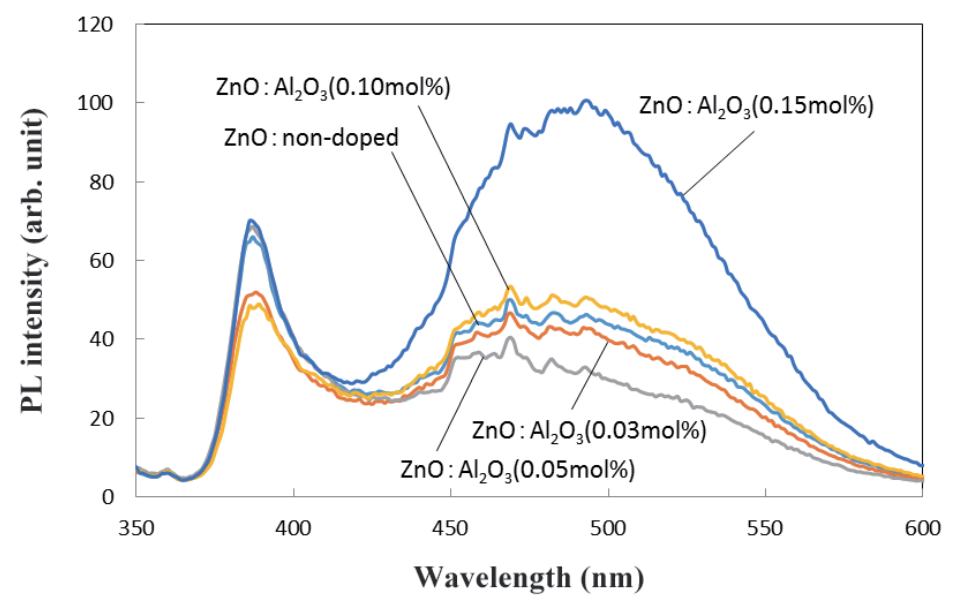

Fig. 5. (Color online) Typical PL spectra of Al-doped $\mathrm{ZnO}$ phosphor in which $\mathrm{Al}_{2} \mathrm{O}_{3}$ concentration was changed from 0.03 to $0.15 \mathrm{~mol} \%$.

doped $\mathrm{ZnO}$ phosphor was higher than that of an In-doped $\mathrm{ZnO}$ phosphor. Typical PL spectra of Indoped $\mathrm{ZnO}$ phosphors are shown in Fig. 6, in which the concentration of $\operatorname{In}_{2} \mathrm{O}_{3}$ was changed from 1.5 to $60 \mathrm{~mol} \%$. Typical PL spectra of the Ga-doped $\mathrm{ZnO}$ phosphors are also shown in Fig. 7, in which $\mathrm{Ga}_{2} \mathrm{O}_{3}$ concentration was changed from 1 to $99 \mathrm{~mol} \%$. In this case, the $\mathrm{ZnO}$ powder supplied by Furuuchi Chemicals Co., Ltd. was also used as the mother phosphor material. The PL peak intensities of the UV emission band in the Ga-doped $\mathrm{ZnO}$ phosphors are plotted in Fig. 8, indicating that the $\mathrm{ZnO}$ phosphor doped with $30 \mathrm{~mol} \% \mathrm{Ga}_{2} \mathrm{O}_{3}$ exhibited the most intense UV emission band without a visible emission band. It was also confirmed that the UV emission band intensity of the Ga-doped $\mathrm{ZnO}$ phosphor prepared using $\mathrm{ZnO}$ powder supplied by Furuuchi Chemicals Co., Ltd. was higher than that of the Ga-doped $\mathrm{ZnO}$ phosphor from Hakusui Chemicals Co., Ltd. 


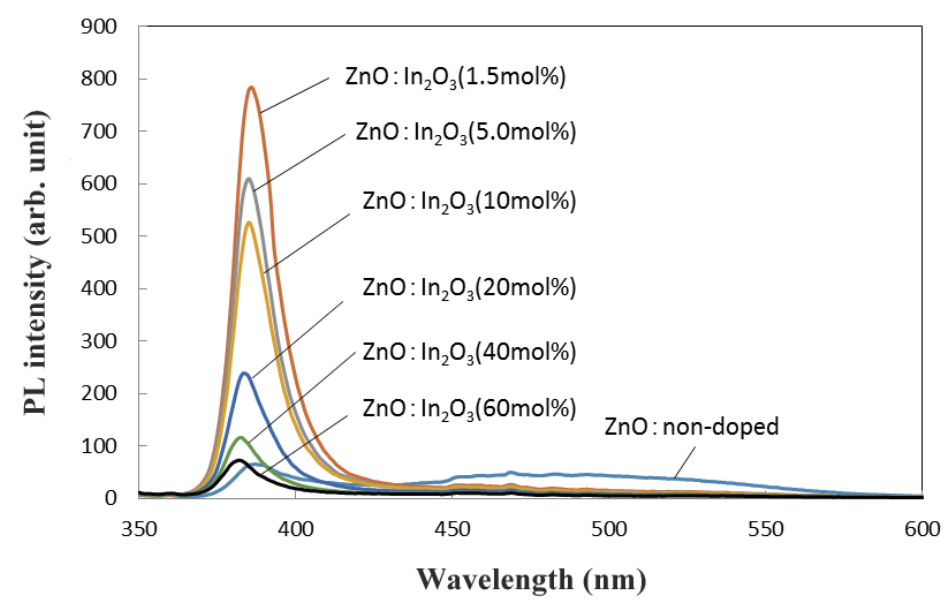

Fig. 6. (Color online) Typical PL spectra of In-doped $\mathrm{ZnO}$ phosphors, in which $\mathrm{In}_{2} \mathrm{O}_{3}$ concentration was changed from 1.5 to $60 \mathrm{~mol} \%$.

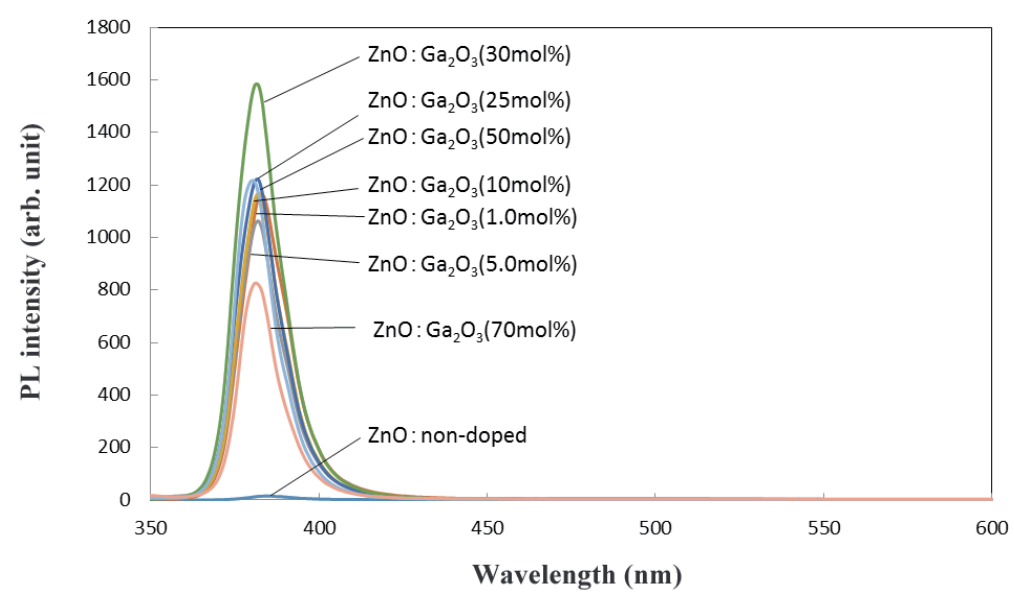

Fig. 7. (Color online) Typical PL spectra of Ga-doped $\mathrm{ZnO}$ phosphors, in which $\mathrm{Ga}_{2} \mathrm{O}_{3}$ concentration was changed from 1 to $70 \mathrm{~mol} \%$.

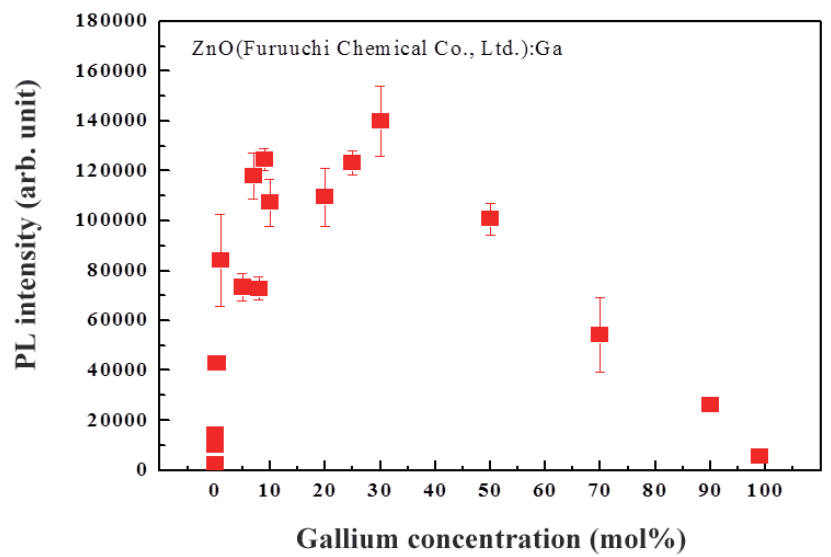

Fig. 8. (Color online) PL intensity of the UV emission band as a function of $\mathrm{Ga}_{2} \mathrm{O}_{3}$ concentration (1.0-99 mol\%) in Ga-doped $\mathrm{ZnO}$ phosphors. 
The normalized PL spectra of Cu-, Al-, In-, and Ga-doped $\mathrm{ZnO}$ phoshpors are shown in Fig. 9, in which the normalization of the spectra was done at the peak of the UV emission band. It was confirmed that the UV band intensity of Ga-doped $\mathrm{ZnO}$ phosphor (Furuuchi Chemicals Co., Ltd.) is comparable to those of other phosphors such as Ga-doped $\mathrm{ZnO}$ (Hakusui Chemicals Co., Ltd.) and In-doped $\mathrm{ZnO}$ and undoped $\mathrm{ZnO}$ (Furuuchi Chemicals Co., Ltd. and Hakusui Chemicals Co., Ltd.).

\subsection{Dependence of PL characteristics on sintering conditions}

It was found that the intensity of the UV emission band of Ga-doped $\mathrm{ZnO}$ phosphor is strongly dependent on the atmosphere and pressure during the phosphor sintering process, especially the pressure of vacuum. The dependence of the PL intensity of the UV band on atmospheric pressure during sintering was therefore investigated for Ga-doped $\mathrm{ZnO}$ (Furuuchi Chemicals Co., Ltd.) phosphors. Figure 10 shows typical PL spectra of the Ga-doped $\mathrm{ZnO}$ phosphors sintered at various vacuum pressures from 7.0 to $10.0 \mathrm{~Pa}$, indicating that the Ga-doped $\mathrm{ZnO}$ phosphor sintered at 8.0 $\mathrm{Pa}$ exhibited the most intense UV emission without the visible emission. It was confirmed that the crystallinity of Ga-doped $\mathrm{ZnO}$ prepared in vacuum (in reducing atmosphere) is better than that prepared in atmospheric pressure, from the results of the XRD experiment. This result strongly suggests that Ga-doped $\mathrm{ZnO}$ phosphor heat-treated in reductive atmosphere has small amounts of native defects that give rise to the visible emission band. The disappearance of the visible emission band at about $500 \mathrm{~nm}$ is ascribed to the strongly reducing atmosphere used in the SPS technique.(19)

\subsection{Effects of $\mathrm{B}_{2} \mathrm{O}_{3}$ doping on PL characteristics}

A scintillator using a Ga-doped $\mathrm{ZnO}$ phosphor cannot interact directly with neutrons. To use the Ga-doped $\mathrm{ZnO}$ scintillator as a neutron detector, it is very effective to dope $\mathrm{B}_{2} \mathrm{O}_{3}$ as a neutron converting material into the phosphor because ${ }^{10} \mathrm{~B}$ interacts with neutrons to emit alpha rays by

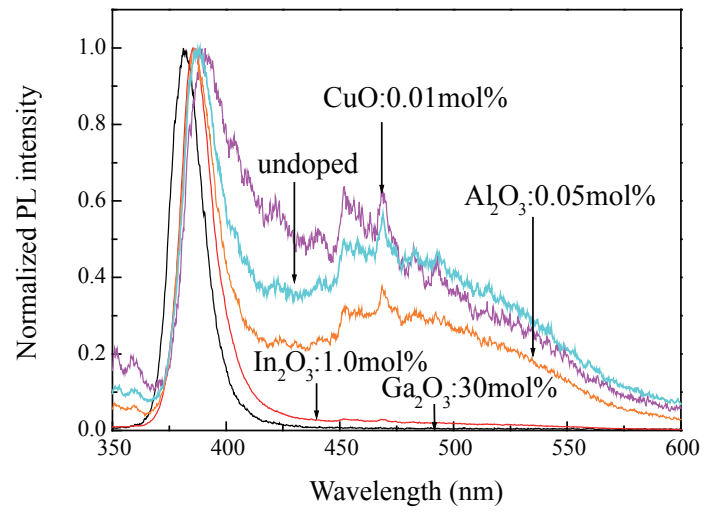

Fig. 9. (Color online) Normalized PL spectra of $\mathrm{Cu}-$, Al-, In-, and Ga-doped $\mathrm{ZnO}$ phoshpors shown in Figs. 4-7, where the normalization of the spectrum was done at the peak intensity of the UV emission band. Each phosphor was sintered at $750{ }^{\circ} \mathrm{C}$ in vacuum for $30 \mathrm{~min}$.

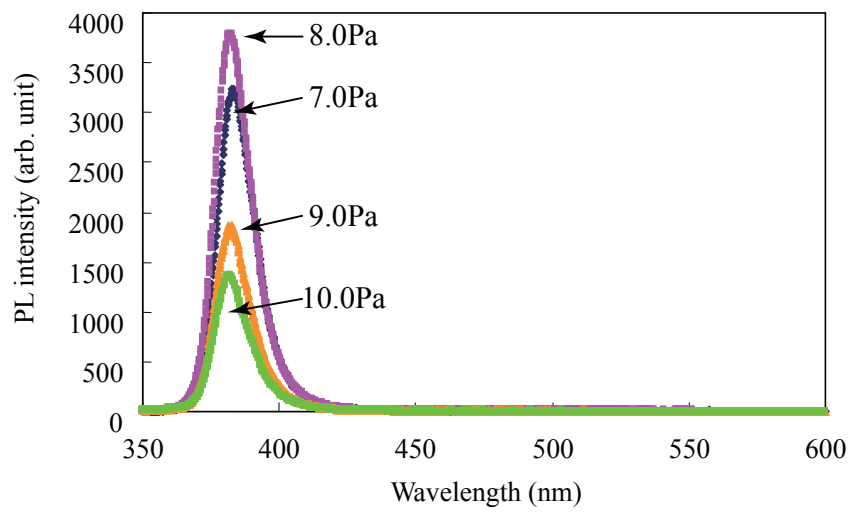

Fig. 10. (Color online) Typical PL spectra of Gadoped $\mathrm{ZnO}$ phosphors sintered at various vacuum pressures from 7.0 to $10.0 \mathrm{~Pa}$ at $750{ }^{\circ} \mathrm{C}$, indicating that Ga-doped $\mathrm{ZnO}$ phosphor sintered at $8.0 \mathrm{~Pa}$ exhibited the most intense UV emission. 
means of the (n, alpha) reaction, and consequently the Ga-doped $\mathrm{ZnO}$ phosphor can be excited by alpha rays to produce luminescence. It is very important to confirm whether or not the UV emission intensity of the Ga-doped $\mathrm{ZnO}$ phosphor changes owing to the addition of $\mathrm{B}_{2} \mathrm{O}_{3}$. To confirm this, the dependence of $\mathrm{PL}$ characteristics on $\mathrm{B}_{2} \mathrm{O}_{3}$ concentration was investigated for the Ga-doped $\mathrm{ZnO}$ phosphor with $\mathrm{B}_{2} \mathrm{O}_{3}$ powder added. It was found that the Ga-doped $\mathrm{ZnO}$ with $30 \mathrm{~mol} \% \mathrm{~B}_{2} \mathrm{O}_{3}$ added exhibited the most intense UV emission, as shown in Fig. 11. It was confirmed that the UV emission intensity is not reduced by doping $\mathrm{B}_{2} \mathrm{O}_{3}$, compared with that of the Ga-doped $\mathrm{ZnO}$ without $\mathrm{B}_{2} \mathrm{O}_{3}$, as shown in Fig. 12.

The PL intensity is not changed by adding $\mathrm{B}_{2} \mathrm{O}_{3}$, the concentration of which was varied from 10 to $50 \mathrm{~mol} \%$, though the Ga-doped $\mathrm{ZnO}$ with $\mathrm{B}_{2} \mathrm{O}_{3}$ added at concentrations above $40 \mathrm{~mol} \%$ exhibited a low PL intensity as shown Fig. 13. From these results, we can say that the PL intensity of the Gadoped $\mathrm{ZnO}$ with $10-30 \mathrm{~mol} \% \mathrm{~B}_{2} \mathrm{O}_{3}$ added was not decreased by adding $\mathrm{B}_{2} \mathrm{O}_{3}$ as a neutron converter. This result strongly suggests that the Ga-doped $\mathrm{ZnO}$ with $\mathrm{B}_{2} \mathrm{O}_{3}$ as a neutron converter is useful as a phosphor for highly efficient neutron detectors, because the scintillator using the Ga-doped $\mathrm{ZnO}$ can be mixed uniformly with the $\mathrm{B}_{2} \mathrm{O}_{3}$ neutron converter.

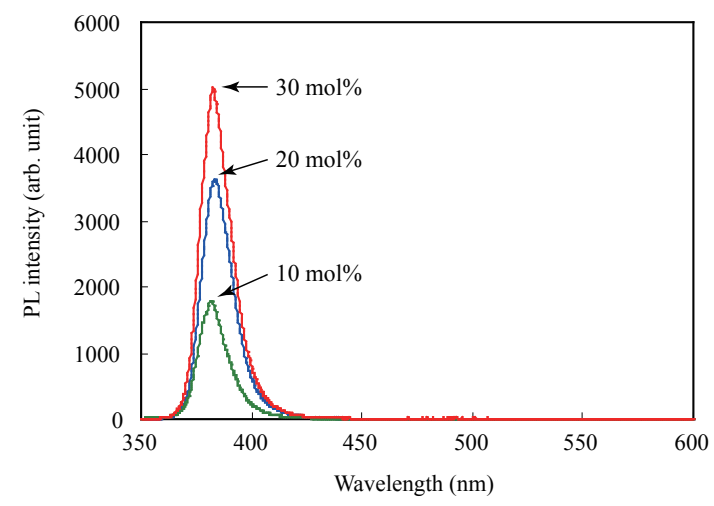

Fig. 11. (Color online) Dependence of UV emission spectra on the concentration of $\mathrm{B}_{2} \mathrm{O}_{3}$ dopant from 10 to $30 \mathrm{~mol} \%$ in Ga-doped $\mathrm{ZnO}$ phosphors, which were sintered at $750{ }^{\circ} \mathrm{C}$ in vacuum.

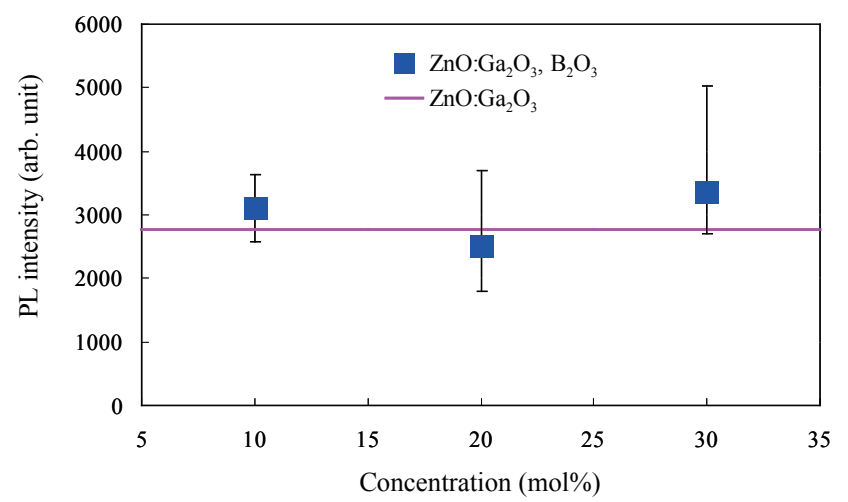

Fig. 12. (Color online) UV emission intensity as a function of $\mathrm{B}_{2} \mathrm{O}_{3}$ concentration in the Ga-doped $\mathrm{ZnO}$. In this case, the $30 \mathrm{~mol} \%$ Ga-doped $\mathrm{ZnO}$ with $30 \mathrm{~mol} \% \mathrm{~B}_{2} \mathrm{O}_{3}$ was sintered at $750{ }^{\circ} \mathrm{C}$ in a reducing atmosphere of 7.0 Pa.

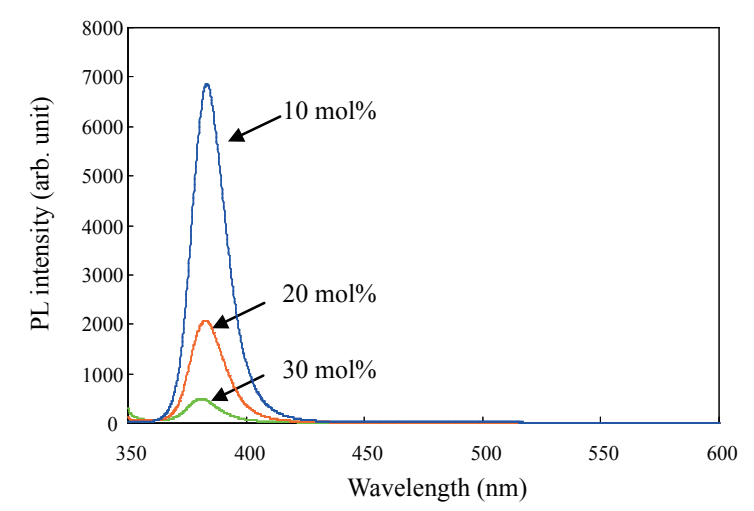

Fig. 13. (Color online) Dependence of PL spectra on the concentration of $\mathrm{H}_{3}{ }^{10} \mathrm{BO}_{3}$ in Ga-doped $\mathrm{ZnO}$ phosphors. The concentration of $\mathrm{H}_{3}{ }^{10} \mathrm{BO}_{3}$ was changed from 10 to $30 \mathrm{~mol} \%$. 


\subsection{XRD results of the Ga-doped $\mathrm{ZnO}$ phosphor}

To estimate the crystallinity of the Ga-doped $\mathrm{ZnO}$ phosphor, the XRD pattern obtained using an XRD apparatus was observed for Ga-doped $\mathrm{ZnO}$ phosphors. Figure 14 shows typical XRD patterns of $\mathrm{Ga}\left(30 \mathrm{~mol} \%\right.$ )-doped $\mathrm{ZnO}$ phosphor with $\mathrm{B}_{2} \mathrm{O}_{3}(30 \mathrm{~mol} \%)$-doped converter powder. The crystal structure of Ga-doped $\mathrm{ZnO}$ phosphor estimated using Joint Committee on Powder Diffraction Standards (JCPDS) data was a mixture of crystalline $\mathrm{ZnO}$ and $\mathrm{ZnGa}_{2} \mathrm{O}_{4}$ without $\mathrm{ZnO}\left(\mathrm{BO}_{2}\right)$ and $\mathrm{B}_{2} \mathrm{O}_{3}$ phases.

Figure 15 shows the UV emission intensity as a function of the full-width at half-maximum (FWHM) of the main diffraction peak at $35.4 \mathrm{deg}$, indicating that the UV emission intensity increased with decreasing FWHM of the diffraction peak. This means that the UV emission intensity increased as the crystallinity of the Ga-doped $\mathrm{ZnO}$ phosphor with a $\mathrm{B}_{2} \mathrm{O}_{3}$-added neutron converter increased, because the smaller the FWHM of the XRD peak is, the better the crystallinity of phosphor is.

\subsection{Response of Ga-doped $\mathrm{ZnO}$ scintillator with $\mathrm{B}_{2} \mathrm{O}_{3}$ converter for neutron beam}

Figure 16 shows a picture of a prototype of a Ga-doped $\mathrm{ZnO}$ scintillator with a $\mathrm{B}_{2} \mathrm{O}_{3}$ converter. A schematic diagram of an ultrahigh-counting-rate neutron beam monitor using Ga-doped $\mathrm{ZnO}$ with $\mathrm{B}_{2} \mathrm{O}_{3}$ phosphor is shown in Fig. 17. The neutrons coming to the monitor react with the $\mathrm{B}_{2} \mathrm{O}_{3}$

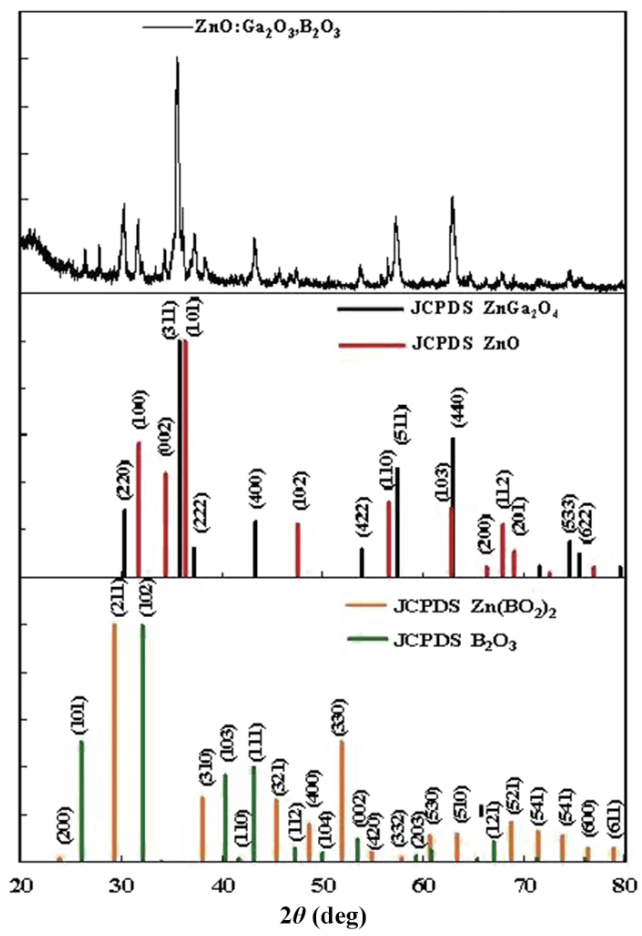

Fig. 14. (Color online) XRD pattern of $30 \mathrm{~mol} \% \mathrm{Ga}-$ doped $\mathrm{ZnO}$ phosphor with $30 \mathrm{~mol} \% \mathrm{~B}_{2} \mathrm{O}_{3}$.

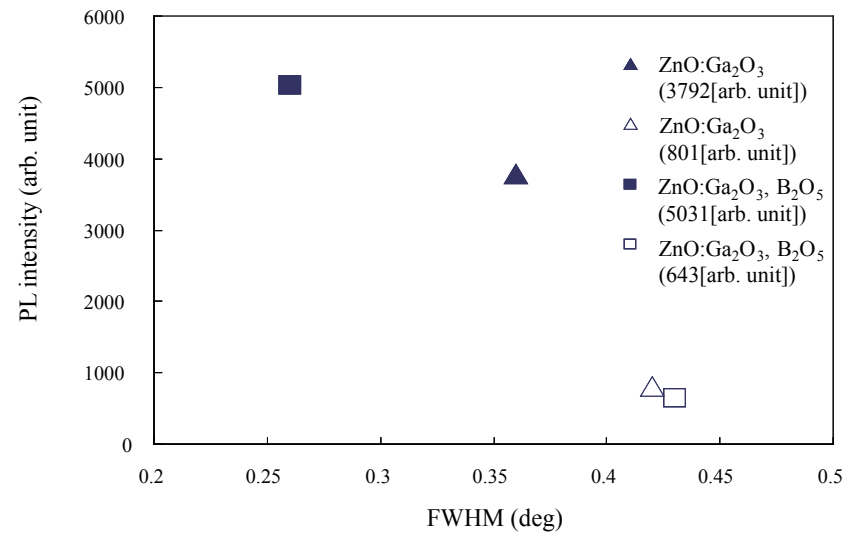

Fig. 15. (Color online) UV emission intensity as a function of the FWHM of the main diffraction peak at $35.4 \mathrm{deg}$ for the Ga-doped $\mathrm{ZnO}$ phosphors. The PL intensities were plotted for Ga-doped $\mathrm{ZnO}$ phosphors with and without $\mathrm{B}_{2} \mathrm{O}_{3}$. 


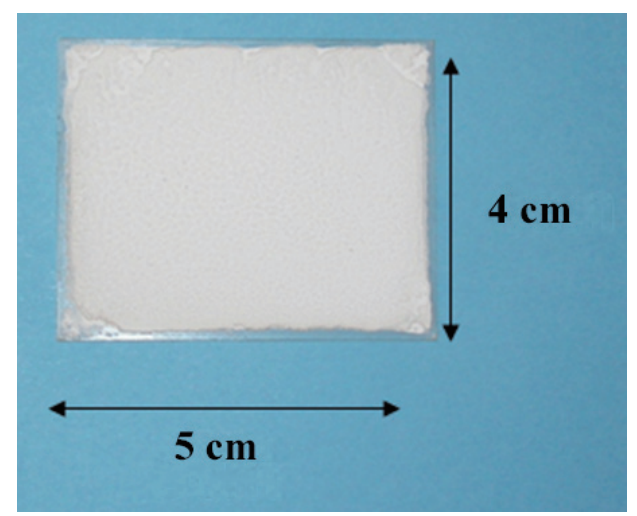

Fig. 16. (Color online) Ga-doped $\mathrm{ZnO}$ scintillator with $\mathrm{B}_{2} \mathrm{O}_{3}$ converter powder.

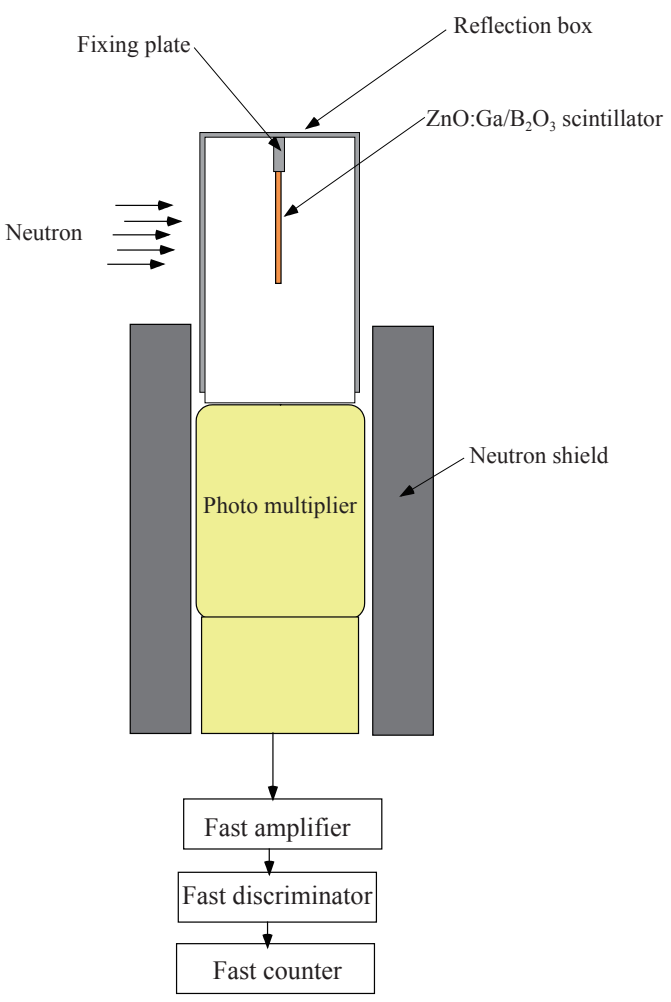

Fig. 17. (Color online) Ultrahigh-countingrate neutron beam monitor using Ga-doped $\mathrm{ZnO}$ scintillator with $\mathrm{B}_{2} \mathrm{O}_{3}$.

converter in the scintillator to produce alpha rays due to the (n, alpha) reaction, and the Ga-doped $\mathrm{ZnO}$ scintillator is excited by alpha rays to emit $380 \mathrm{~nm}$ light (UV emission band due to exciton emission).

To check the radioluminescence spectrum of the Ga-doped $\mathrm{ZnO}$ phosphor by excitation with alpha rays, the radioluminescence from the Ga-doped $\mathrm{ZnO}$ with $\mathrm{H}_{3}{ }^{10} \mathrm{BO}_{3}$ neutron converter powder was observed using alpha rays from a ${ }^{241} \mathrm{Am}$ source, because $\mathrm{H}_{3}{ }^{10} \mathrm{BO}_{3}\left({ }^{10} \mathrm{~B}\right.$ amount is larger than $92.4 \%$ ) is commonly used as a neutron converter. ${ }^{(22)}$ It was found that an intense UV emission can be observed in the radioluminescence of the Ga-doped $\mathrm{ZnO}$ with $\mathrm{H}_{3}{ }^{10} \mathrm{BO}_{3}$ powder, as shown in Fig. 18. It was confirmed that the decay time of the UV emission band was about $20 \mathrm{~ns}$, which is slightly long compared with that (4 ns) reported previously. The difference in decay time is ascribed to the difference in excitation source, because phosphor is excited over the band gap to generate carriers in the case of radioluminescence. This result strongly suggests that the Ga-doped $\mathrm{ZnO}$ powder phosphor with $\mathrm{H}_{3}{ }^{10} \mathrm{BO}_{3}$ neutron converter powder is useful as a phosphor material for neutron scintillators with a very short lifetime.

Figure 19 shows responses of the neutron beam monitor using the Ga-doped $\mathrm{ZnO}$ scintillator with a $\mathrm{B}_{2} \mathrm{O}_{3}$ converter as a function of reactor power from the Japan Research Reactor-3 (JRR3) compared with those of the Ag-doped $\mathrm{ZnS}$ scintillator with a $\mathrm{B}_{2} \mathrm{O}_{3}$ converter and a vanadium ${ }^{(21)}$ scatter plate for $\mathrm{X}$-rays on the Ag-doped $\mathrm{ZnO}$ scintillator with a $\mathrm{B}_{2} \mathrm{O}_{3}$ converter. The response of the Ga-doped $\mathrm{ZnO}$ scintillator mixed with $\mathrm{B}_{2} \mathrm{O}_{3}$ converter powder for neutron beams was fairly good compared with that of the Ag-doped $\mathrm{ZnS}$ scintillator. 


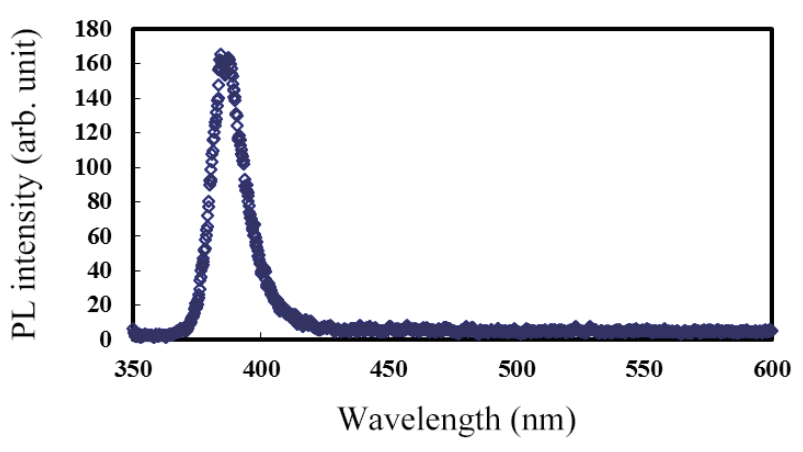

Fig. 18. Typical radioluminescent spectrum for alpha rays $\left({ }^{241} \mathrm{Am}\right.$ source) irradiated $\mathrm{Ga}$-doped $\mathrm{ZnO}$ with $\mathrm{H}_{3}{ }^{10} \mathrm{BO}_{3}$ neutron converter.

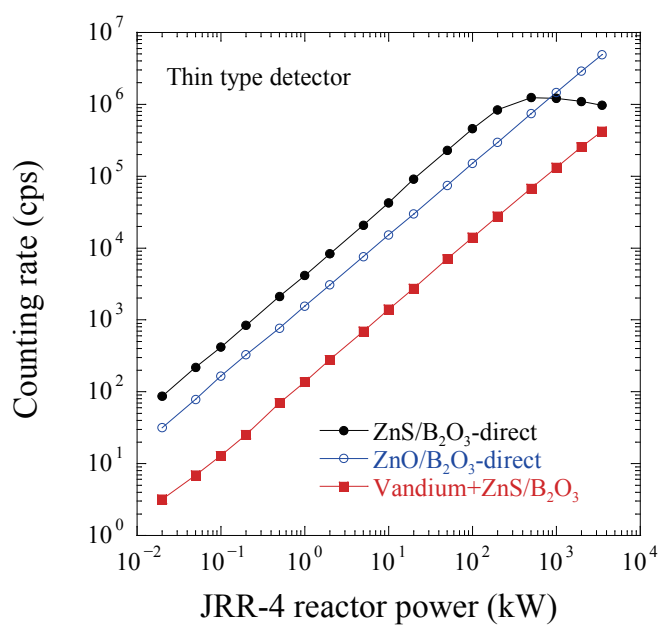

Fig. 19. (Color online) Response of the neutron beam monitor using $\mathrm{ZnO}: \mathrm{Ga}_{2} \mathrm{O}_{3} / \mathrm{B}_{2} \mathrm{O}_{3}$ scintillator as a function of the reactor power, compared with that of $\mathrm{ZnS}: \mathrm{Ag} / \mathrm{B}_{2} \mathrm{O}_{3}$ scintillator and $\mathrm{ZnS}: \mathrm{Ag} / \mathrm{B}_{2} \mathrm{O}_{3}$ covered with the vanadium filter for $\mathrm{X}$-ray scattering.

\section{Conclusions}

The $\mathrm{ZnO}$ family of phosphors for neutron detectors was prepared using the SPS method. The optical properties of the $\mathrm{ZnO}$ phosphors were investigated. The following results were obtained.

(1) Two dominant PL emission peaks at 383 and $495 \mathrm{~nm}$ were observed.

(2) The lifetime of the PL emission peak at $383 \mathrm{~nm}$ (UV emission band) is about $20 \mathrm{~ns}$, which is suitable for neutron detection.

(3) The Ga (30 mol\%)-doped $\mathrm{ZnO}$ phosphor exhibited intense UV emission without visible emission.

(4) The Ga-doped $\mathrm{ZnO}$ phosphor can be prepared under an atmospheric pressure of about $8 \mathrm{~Pa}$ using the SPS method.

(5) The PL intensity of the UV emission band was increased by improving the crystallinity of the $\mathrm{ZnO}$ phosphor.

(6) The PL intensity of Ga-doped $\mathrm{ZnO}$ with $10-30 \mathrm{~mol} \% \mathrm{~B}_{2} \mathrm{O}_{3}$ added was not reduced by adding $\mathrm{B}_{2} \mathrm{O}_{3}$ as the neutron converter.

(7) The response of the Ga-doped $\mathrm{ZnO}$ scintillator mixed with $\mathrm{B}_{2} \mathrm{O}_{3}$ converter powder to the neutron beam from the JRR-3 facility was fairly good compared with that of the Ag-doped $\mathrm{ZnS}$ scintillator.

\section{Acknowledgements}

The authors wish to thank Mr. F. Motoya, Mr. H. Kurokawa, and Mr. A. Michii from the Kanazawa Institute of Technology for their excellent assistance in the experiments. This work was partly supported by a Grant-in-aid (15K13359) from the Ministry of Education, Culture, Sports, Science and Technology of Japan and the Cooperative Research Project of Research Institute of Electronics, Shizuoka University. 


\section{References}

1 M. Katagiri: Nucl. Instrum. Methods Phys. Res, Sect. A 529 (2004) 254.

2 U. Orgur, Y. I. Alivov, C. Liu, A. Teke, M. A. Reshchikov, S. Dogan, V. Avrutin, S. J. Cho, and H. Morkoc: J. Appl. Phys. 98 (2005) 041301.

3 Y. S. Choi, D. K. Hwang, M. S. Oh, K. P. Hong, V. T. Em, H. W. Choi, and S. J. Park: J. Electrochem. Soc. 155 (2008) H909.

4 E. I. Gorokhova, G. V. Ananeva, V. A. Demidenko, P. A. Rodnyi, I. V. Khodyuk, and E. D. Bourret-Courchesne: J. Opt. Technol. 75 (2008) 741.

5 Y. Fujimoto, T. Yanagida, H. Sekiwa, Y. Yokota, V. Chani, and A. Yoshikawa: Jpn. J. Appl. Phys. 50 (2011) 01BG04-1.

6 M. J. F. Empizo, K. Yamanoi, K. Fukuda, R. Arita, Y. Minami, T. Shimizu, N. Sarukura, T. Fukuda, A. B. Santos-Putungan, R. M. Vargas, A. A. Salvador, and R. V. Sarmago: J. Ceramic Processing Res. 16 (2015) 98.

7 E. Oshima, H. Ogino, I. Niikura, K. Maeda, M. Sato, M. Ito, and T. Fukuda: J. Cryst. Growth 260 (2004) 166.

8 T. Kawachi, M. Kado, M. Tanaka, A. Sasaki, N. Hasegawa, A. V. Kilpio, S. Namba, K. Nagashima, P. Lu, K. Takahashi, H. Tang, R. Tai, M. Kishimoto, M. Koike, H. Daido, and Y. Kato: Phys. Rev. A 66 (2002) 33815.

9 H. Nanto, T. Minami, S. Shooji, and S. Takata: J. Appl. Phys. 55 (1984) 1029.

10 T. Minami, H. Sato, H. Nanto, and S. Takata: Jpn. J. Appl. Phys. 24 (1985) L781.

11 H. Nanto, T. Minami, and S. Takata: J. Appl. Phys. 60 (1986) 482.

12 H. Nanto, H. Sokooshi, and T. Kawai: Sens. Actuators, B 13-14 (1993)715.

13 H. Nanto, T. Morita, H.Habara, K. Kondo, Y. Douguchi, and T. Minami: Sens. Actuators, B 35-36 (1996) 384.

14 J. Pejchal, Y. Kagamitani, D. Ehrentraut, H. Sato, H. Okada, H. Hatanaka, M. Nikl, A. Yoshikawa, H. Fukumura, and T. Fukuda: Phys. Status Solidi C 4 (2007) 942.

15 P. A. Rodnyi, G. B. Stryganyuk, and I. V. Khodyuk: Opt. Spectrosc. 104 (2008) 210.

16 M. Katagiri, K. Sakasai, M. Matsubayashi, T. Nakamura, Y. Kondo, Y. Chujo, H. Nanto, and T. Kojima: Nucl. Instrum. Methods Phys. Res, Sect. A 529 (2004) 274.

17 N. Kubota, M. Katagiri, K. Kamijo, and H. Nanto: Nucl. Instrum. Methods Phys. Res, Sect. A 529 (2004) 321.

18 A. Nishimura, A. Kinoshita, A. Fujiwara, S. Koyama, Y. Takei, H. Nanto, and M. Katagiri: Ionizing Radiat. 34 (2008) 65 (in Japanese).

19 V. A. Demidenko, E. I. Gorokhova, I. V. Khodyuk, O. A. Khristich, S. B. Mikhrin, and P. A. Rodnyi: Radiat. Meas. 42 (2007) 549.

20 T. Yanagida, Y. Fujimoto, M. Miyamoto, and H. Sekiwa: Jpn. J. Appl. Phys. 53 (2014) 02BC13.

21 http://www.isis.stfc.ac.uk/instruments/neutron-diffraction2593.html

22 Y. Wang, S. Han, L. Hao, L. He, G. Wei, M. Wu, H.Wang, Y. Liu, and D. Chen: Phys. Procedia 43 (2013) 216. 